\title{
Decapod crab zoeae as food for rearing cephalopod paralarvae
}

\author{
Roger Villanueva* \\ Instituto de Ciencias del Mar (CSIC), Paseo Joan de Borbó s/n, 08039 Barcelona, Spain \\ Observatoire Océanologique de Banyuls, Laboratoire Arago, F-66650 Banyuls-sur-Mer, France
}

Accepted 25 July 1994

\begin{abstract}
A simple method of providing a regular supply of live food for the experimental culture of paralarval cephalopods is described. The primary food source utilized was hatched zoeae of large laboratory populations of the hermit crab, Pagurus prideaux. Zoeal size, swimming behaviour, and distribution in the water column make these zoeae a suitable live prey for rearing early post-hatching planktonic stages of cephalopods and probably other marine zooplanktivores. Ovigerous $P$. prideaux females were collected from the sea throughout the year at depths between 10 and $90 \mathrm{~m}$ in the NW Mediterranean and maintained at densities of up to 500 specimens $\cdot \mathrm{m}^{-2}$. One month after spawning in aquaria, $38 \%$ of the females of $P$. prideaux started to incubate a second clutch of eggs. Other decapod crustacean species, such as Liocarcinus depurator and Dardanus arrosor, were maintained to use their zoeae as a food source for cephalopod paralarvae. $P$. prideaux zoeae were used as the sole or main food resource for rearing Loligo vulgaris and Octopus vulgaris, during the first 2 months of life. First feeding and initial growth in $L$. vulgaris and $O$. vulgaris paralarvae can be successfully stimulated using decapod zoeae with a total length equivalent to $50-100 \%$ of the cephalopod's mantle length.
\end{abstract}

Keywords: Cephalopoda; Feeding and nutrition / cephalopods; Loligo vulgaris; Octopus vulgaris; Larviculture

\section{Introduction}

The hatchling cephalopod paralarvae are planktonic and carnivorous, and require live prey of a critical size and suitable swimming behaviour. Under culture conditions, failure of first feeding and starvation are among the primary causes of mortality in cephalopods, particularly during the vulnerable planktonic stages (Boletzky and Hanlon, 1983; Hanlon, 1987). The lack of a sufficient quantity of suitable food is one of the main impediments to

\footnotetext{
* Present address: Instituto de Ciencias del Mar (CSIC), Paseo Joan đe Borbó s/n, 08039 Barcelona, Spain.
} 
developing experimental and mass culture of the delicate paralarval stage of cephalopods. The use of the common brine shrimp, Artemia sp., as the sole food source for the planktonic stages has met with limited success in recent studies (Hamazaki et al., 1991), and a variety of food sources has been tested, with greater or lesser success (see reviews by Boletzky, 1974, 1989; Boletzky and Hanlon, 1983). Cultures of cephalopods have been raised successfully using natural zooplankton collected at sea (see Turk et al., 1986; Yang et al., 1986; Hanlon et al., 1989, among others), but this method of rearing requires a substantial input of both time and effort, and it is difficult to determine reliably the precise species and size of prey taken by the paralarvae. On the other hand, females of the palaemonid shrimp, Palaemon serrifer, have also been used successfully as a source of zoeae as food for planktonic paralarval octopodids (Itami et al., 1963).

Feeding studies carried out on natural populations have revealed that small planktonic crustaceans contribute a major portion of the diets of such cephalopod stages (Vecchione, 1987; Passarella and Hopkins, 1991), and the zoeae of decapod crustaceans have been found in the stomach contents of paralarval squids (Vecchione, 1991). The present paper describes a simple method of obtaining decapod crustacean zoeae for rearing planktonic paralarval and juvenile cephalopods. The crustacean mainly used was Pagurus prideaux Leach, a pagurid crab of moderate size that is always found in association with the sea anemone Adamsia carciniopados (Otto) (Ross, 1984). A complete description of the larval morphology of $P$. prideaux, from the first zoeal stage to the glaucothoeal stage, is given by Goldstein and Bookhout (1972). The same authors reported that females of $P$. prideaux may spawn several times between moults, under laboratory conditions. $P$. prideaux is present throughout the Eastern Atlantic from Bergen in Norway to the Cape Verde Islands, and in the Mediterranean Sea, at depths between 7 and $250 \mathrm{~m}$ (Ingle, 1993).

Ovigerous females of two other decapod species abundant in the local crustacean fauna, namely the hermit crab Dardanus arrosor (Herbst) and the portunid crab Liocarcinus depurator (Linnaeus), were maintained in lower numbers but in a similar manner to $P$. prideaux. Zoeal morphology of both species is given by Ingle (1991). Liocarcinus depurator is the most abundant brachyuran crab on the muddy bottoms of the NW Mediterranean continental shelf (Abelló et al., 1988); the main spawning period begins in November and lasts until January. However, ovigerous females occur throughout the year, each producing between 30000 and 230000 eggs (Abelló, 1989).

\section{Materials and methods}

\section{Collection of ovigerous females of Pagurus prideaux}

Specimens of $P$. prideaux were collected at depths between 10 and $20 \mathrm{~m}$ in Banyuls Bay (NW Mediterranean) using a sledge net trawled in daytime, from a small boat at a mean speed of 2 knots, from October 1992 to April 1993. Tow duration was approximately 15 min. Ovigerous females were removed from the catch on board and transported directly to the aquarium at the Laboratoire Arago for maintenance. Post-catch mortality was very low. From May to October 1993, when this species became scarce inshorc, large numbers of individuals were collected by commercial trawlers operating in the zone between 60 and $90 \mathrm{~m}$ of depth, off Port Vendres. These vessels used a bottom trawl, and haul duration was 
around $4 \mathrm{~h}$. Ovigerous females were removed from the catch on board. The mortality rate among these ovigerous females caught by such trawls in the 2 or 3 days following capture was high (around $25 \%$ ), probably due to physical and thermal shock. Pagurus prideaux is caught routinely by fishermen off Llança (NE Spain), between 10 and $30 \mathrm{~m}$ of depth using cylindric basket wire traps of $65 \mathrm{~cm}$ length and $30 \mathrm{~cm}$ diameter, known locally as 'guixoneres', $P$. prideaux being used as bait in the long-line sparid fishery. These traps collected large numbers of individuals from November 1993 to April 1994. This method of capture is both highly effective and less traumatic than trawling, so post-catch mortality is practically absent. The number of eggs was counted from 30 ovigerous females ranging in size between 14.8 and $20.4 \mathrm{~mm}$ of shield length (SL) (mean $=16.5 \mathrm{~mm}, \mathrm{~s} . \mathrm{d} .=1.4$ ). Eggs were counted using a dissecting microscope at $\times 10$ magnification, spreading the eggs out on a dish. The size of the females was obtained by measuring the SL with calipers.

\section{Rearing conditions of Pagurus prideaux}

Running seawater was circulated through the holding tanks. Water temperatures ranged from $9.5^{\circ} \mathrm{C}$ in March to $21^{\circ} \mathrm{C}$ in August, and salinity was around $38 \%$. The crabs were fed chopped fish and cephalopods twice a week. $P$. prideaux specimens were kept under a natural day/night photoperiod at densities up to $450-500$ specimens $\cdot \mathrm{m}^{-2}$. High maintenance densities of this species are feasible, because under aquarium conditions $P$. prideaux exhibits increased aggregational behaviour at high stocking densities (Meadows and Mitchell, 1973), with a low level of intraspecific aggressiveness (Hazlett, 1981). P. prideaux females were assigned to one of 3 rectangular tanks depending upon their sexual maturity stage, which was determined according to the scale of Fotheringham (1980).

Tank 1 contained only maturing ovigerous females. These specimens had orange eggs in the egg sac, and the embryos lacked eyespots. The tank had a capacity of 220 litres and measured $248 \times 80 \mathrm{~cm}$. The water depth was $10 \mathrm{~cm}$, and the mean flow rate was around 400 $1 \cdot \mathrm{h}^{-1}$.

Tank 2 contained only ovigerous females with eggs that were on the point of hatching. The eggs of these females were grayish brown, and the embryos had clearly discernible eyespots. This tank had opaque sides and a capacity of 140 litres and was $100 \times 60 \mathrm{~cm}$ in size. The water level was $15 \mathrm{~cm}$, and the mean flow rate was approximately $1001 \cdot \mathrm{h}^{-1}$. The half of the tank near the outlet was covered by an opaque lid to provide a shaded area so that the zoeae, which exhibit positive phototactic behaviour, would concentrate in the lighted portion of the tank, far from the outlet. To avoid any loss of zoeae, the tank outlet discharged into a smaller aquarium measuring $40 \times 25 \mathrm{~cm}$ with a water level of $15 \mathrm{~cm}$ and a $250-\mu \mathrm{m}$ filter to retain the zoeae. The females in this tank 2 were not fed, in order to achieve the highest possible water quality and reduce the likelihood of organic pollution contaminating the cephalopod cultures following collection of the zoeae. The tank was cleaned daily by siphoning, combined with increased water influx.

Tank 3 contained immature, non-ovigerous and spent females and some males. Culture conditions were the same as in tank 1 . The sexual maturity stage of the females in the 3 tanks was checked weekly, and the specimens were re-assigned to the tanks according to their current malurity stage.

In addition, ovigerous females of two other decapod species that are abundant in the local crustacean fauna, namely the hermit crab Dardanus arrosor and the portunid crab Liocar- 
cinus depurator, were maintained in separate tanks, in lower numbers but in a similar manner to $P$. prideaux, to use their zoeae as a food source for cephalopod paralarvac.

To determine the percentage of spent $P$. prideaux females which undergo a second maturation during the month after spawning, groups of spent females that spawned in tank 2 during the same week, were monitored. In this way, 3 groups of 38,40 , and 22 spent $P$. prideaux females corresponding to 3 successive weeks (between 27 October and 16 November 1993) were assigned to 3 respective tanks. These tanks measured $60 \times 40 \mathrm{~cm}, 15 \mathrm{~cm}$ of water depth, and the mean flow rate was around $1001 \cdot \mathrm{h}^{-1}$. Females of each group ranging in size between 12 and $22 \mathrm{~mm}$ of SL (mean $=17.6 \mathrm{~mm}, \mathrm{s.d} .=2.1$ ); 13 and $21 \mathrm{~mm}$ of SL $($ mean $=17 \mathrm{~mm}, \mathrm{s.d}=1.8)$ and $13-19 \mathrm{~mm}$ of SL $($ mean $=16.1 \mathrm{~mm}, \mathrm{~s} . \mathrm{d} .=1.3)$, respectively. All together they ranged in size between 12 and $22 \mathrm{~mm}$ of SL (mean $=16.99 \mathrm{~mm}$, s.d. $=1.9, n=100)$. Water temperatures ranged from 13.5 to $16^{\circ} \mathrm{C}\left(\right.$ mean $\left.=14.8^{\circ} \mathrm{C}\right)$, and specimens were fed twice a week.

\section{Zoeal characteristics}

Total length (TL) and carapace length (CL) were obtained in 30 newly hatched zoeae of $P$. prideaux, $D$. arrosor and $L$. depurator, using a dissecting microscope at $\times 40$ magnification equipped with an ocular micrometer. Total fresh weight (TW) of each zoea was obtained using a microbalance Perkin-Elmer AD-4 Autobalance. Length and fresh weight of the newly hatched zoeae are shown in Table 1 . No effort was made to rearing newly hatched zoeae to advanced zoeal stages, and only recently hatched zoeae were used as food for the cephalopod paralarvae.

\section{Cephalopod rearing methods}

Four rearing experiments with paralarval cephalopods were made: two using Loligo vulgaris and two with Octopus vulgaris. Running filtered seawater was circulated through the holding tanks. Mantle lengths (ML) were obtained in 30 newly hatched L. vulgaris and in 30 O. vulgaris.

\section{Table 1}

Carapace length (CL), total length (TL) in mm, and total fresh weight (TW) in $\mathrm{mg}$, from 30 newly hatched zoeae of Liocarcinus depurator, Pagurus prideaux and Dardanus arrosor

\begin{tabular}{llll}
\hline & Mean & Range & s.d. \\
\hline L. depurator & & & \\
CL & 0.52 & $0.45-0.55$ & 0.03 \\
TL & 1.29 & $1.17-1.37$ & 0.05 \\
TW & 0.023 & $0.018-0.03$ & 0.004 \\
& & & \\
$P$. prideaux & & & 0.07 \\
CL & 1.18 & $1.1-1.3$ & 0.12 \\
TL & 3.14 & $2.8-3.3$ & 0.02 \\
TW & 0.316 & $0.273-0.359$ & \\
& & & 0.1 \\
D. arrosor & & & 0.19 \\
CL & 1.44 & $1.3-1.6$ & 0.052 \\
TL & 3.06 & $2.8-3.2$ & $0.224-0.389$ \\
TW & 0.289 & & \\
\hline
\end{tabular}

s.d. $=$ standard deviation. 
With Loligo vulgaris two experiments were made at different temperatures: LV1 and LV2. Experiment LV1 started with individuals hatched on 11 January 1993; the squids were reared for 60 days, when temperature ranged from 9.5 to $12^{\circ} \mathrm{C}$ (mean $=10.9^{\circ} \mathrm{C}$ ). Experiment LV2 started with individuals hatched on 12 July 1993; the squids were reared for 50 days and temperature ranged from 17.5 to $21^{\circ} \mathrm{C}$ (mean $=19.2^{\circ} \mathrm{C}$ ). Both experiments were made using black plastic bags, cylindrical in form. The plastic used was polythene, $0.2 \mathrm{~mm}$ in thickness. The plastic bags had a capacity of 13 litres, they were $20 \mathrm{~cm}$ in diameter and the water level was $42 \mathrm{~cm}$. The mean flow rate was around $351 \cdot \mathrm{h}^{-1}$. In both experiments the initial number of individuals was estimated at 1000 . Mortality was determined by siphoning the bottom when cleaning the plastic bags. During both experiments, periodic tetracycline staining was applied for analysis of growth; results will be published shortly (Villanueva and Boletzky, unpublished data),

With Octopus vulgaris, two experiments were made: OV1 and OV2. Experiment OV1 started with 600 individuals hatched on 23 October 1993; they were reared for 32 days and temperature ranged from 19 to $24^{\circ} \mathrm{C}$ (mean $=21.6^{\circ} \mathrm{C}$ ). The experiment was made using a cylindrical plastic tank, black in colour, with a capacity of 33 litres, $40 \mathrm{~cm}$ in diameter, with the water level at $26 \mathrm{~cm}$. The mean flow rate was $901 \cdot h^{-1}$. The $O V 2$ experiment started with 650 individuals hatched on 1 March 1994; they were reared for 60 days and temperature ranged from 19 to $23^{\circ} \mathrm{C}$ (mean $=21.2^{\circ} \mathrm{C}$ ). The experiment was made using a cylindrical plastic tank, black in colour, with a capacity of 50 litres, $40 \mathrm{~cm}$ in diameter with the water level at $40 \mathrm{~cm}$. The mean flow rate was $1201 \cdot \mathrm{h}^{-1}$. During both experiments, mortality rates

Table 2

Food composition (as percentage) used during the experiments with Loligo vulgaris (LV1 and LV2) and Octopus vulgaris (OV1 and OV2), grouped for every 10 days

\begin{tabular}{|c|c|c|c|c|}
\hline $\begin{array}{l}\text { Number of } \\
\text { days }\end{array}$ & LV1 & LV2 & OV1 & OV2 \\
\hline \multirow[t]{3}{*}{$1-10$} & PP $(100 \%)$ & $\mathrm{PP}(72 \%)$ & $\operatorname{LD}(50 \%)$ & $\operatorname{LD}(92 \%)$ \\
\hline & & $\mathrm{DA}(38 \%)$ & PP $(40 \%)$ & PP $(8 \%)$ \\
\hline & & & $\mathrm{AN}(10 \%)$ & . \\
\hline \multirow[t]{3}{*}{$11-20$} & PP (100\%) & $\mathrm{PP}(50 \%)$ & LD $(23 \%)$ & $\mathrm{LD}(23 \%)$ \\
\hline & & $\mathrm{DA}(50 \%)$ & $\operatorname{PP}(71 \%)$ & $\mathrm{PP}(75 \%)$ \\
\hline & & & AN (6\%) & $\mathrm{AG}(2 \%)$ \\
\hline \multirow[t]{3}{*}{$21-30$} & PP (100\%) & $\mathrm{PP}(80 \%)$ & $\mathrm{LD}(20 \%)$ & $\mathrm{LD}(6 \%)$ \\
\hline & & DA $(20 \%)$ & $\mathrm{PP}(75 \%)$ & PP $(92 \%)$ \\
\hline & & & $\mathrm{AG}(5 \%)$ & MS $(2 \%)$ \\
\hline \multirow[t]{2}{*}{$31-40$} & PP $(100 \%)$ & $\mathrm{PP}(25 \%)$ & - & $\mathrm{PP}(93 \%)$ \\
\hline & & $\operatorname{MS}(75 \%)$ & & $\operatorname{MS}(7 \%)$ \\
\hline \multirow[t]{3}{*}{$41-50$} & PP (100\%) & MS $(100 \%)$ & - & $\mathrm{PP}(70 \%)$ \\
\hline & & & & MS (15\%) \\
\hline & & & & OV $(15 \%)$ \\
\hline \multirow[t]{2}{*}{$51-60$} & PP (100\%) & - & - & $\mathrm{PP}(10 \%)$ \\
\hline & & & & OV $(90 \%)$ \\
\hline
\end{tabular}

$\mathrm{PP}=$ Pagurus prideaux zoeae; $\mathrm{DA}=$ Dardanus arrosor zoeae $; \mathrm{LD}=$ Liocarcinus depurator zoeae; $\mathrm{AN}=$ Artemia nauplii $; \mathrm{AG}=$ Artemia $(3-6 \mathrm{~mm}$ length $) ; \mathrm{MS}=$ mysidacean shrimp $(5-15 \mathrm{~mm}$ length); $\mathrm{OV}=$ ovaries of Carcinus maenas (portions of 5-10 $\mathrm{mm}$ ). 
were determined daily when siphoning the bottom of the tank. Detailed growth data will be published shortly (Villanueva, unpublished data).

Zoeal species composition used as food during the four experiments are shown in Table 2. Feeding was offered at ad libitum levels, although the number of days where ad libitum levels were not reached represented $6,6,3$ and $7 \%$ of the total number of the days of the LV1, LV2, OV1 and OV2 experiments, respectively. Additions of food were made between 2 and 6 times per day. Prey density after addition of food ranged from 100 to $300 \mathrm{zoeae} \cdot 1^{-1}$.

\section{Results}

\section{Zoeal characteristics}

Ovigerous female $P$. prideaux were collected at sea and mantained in aquaria all the year round. The number of eggs per female ranged from 649 to 4153 (mean $=2640$ eggs, s.d. $=870.7, n=30$ females). This number may be slightly higher than the final number of hatched zoeae since in other species of hermit crabs some eggs are lost, probably as a result of mechanical damage (Ameyaw-Akumf, 1975; Fotheringham, 1980). Maturing females with orange eggs need from 4 to 7 weeks for the eggs to develop to the point of hatching, when brown embryos show distinct eyespots. From that point, zoeae hatched during the following 2 weeks. Within a month after spawning, $38 \%$ of the females started to incubate a second clutch of eggs in the egg sac. The size of these monitored females that resumed maturation ranged from 14 to $22 \mathrm{~mm} \mathrm{SL}$ (mean $=17.0 \mathrm{~mm}, \mathrm{s.d}=1.8, n=38$ ) and did not differ from the other non-maturing females of the same group, which ranged from 12 to 22 $\mathrm{mm} \mathrm{SL}$ ( mean $=16.9 \mathrm{~mm}$, s.d. $=1.9, n=62$ ). The mortality rate during this month after spawning was $12 \%$.

The zoeae hatched only at night, mostly during the first hour of darkness. All the zoeae of an individual female hatched over a time span of a few minutes. During hatching the female protruded her abdomen and egg sac out of the shell and vigorously shook the pleopods, thus shedding the zoeae. Thanks to their pronounced phototactic behaviour, zoeae were readily collected by shining a torch or lamp on the surface of the tank, causing the zoeae to concentrate around the light source. After hatching the zoeae swam actively both near the surface and throughout the water column. This behaviour makes them available to paralarval and juvenile cephalopods that inhabit the entire water column (i.e., Loligo vulgaris and Octopus vulgaris). Survival time of the zoeae in the water column in the absence of food was between 36 and $48 \mathrm{~h}$.

\section{Cephalopod rearing experiments}

Loligo vulgaris at hatching ranged in size from 2.95 to $3.15 \mathrm{~mm} \mathrm{ML} \mathrm{(mean}=3.06 \mathrm{~mm}$, s.d. $=0.05, n=30$ ). L. vulgaris was reared at cold temperatures (mean $=10.9^{\circ} \mathrm{C}, \mathrm{LV} 1$ experiment), from hatching to 60 days of age using $P$. prideaux zoeae as the sole food source (Table 2). This batch attained at 30 days a survival rate of $16.8 \%$ and a mean size of $4.6 \mathrm{~mm}$ ML. At 60 days the survival rate was $0.4 \%$ and specimens reached a size of 6.4 $\operatorname{mmML}$.

Loligo vulgaris was also reared at warm temperatures (mean $=19.2^{\circ} \mathrm{C}, \mathrm{LV} 2$ experiment), using zoeae of $P$. prideaux as a main source of food, mixed with zoeae of the hermit crab, 
Dardanus arrosor (Table 2). L. vulgaris individuals prefer $P$. prideaux to $D$. arrosor zoeae when both zoeae were presented together, and only captured $D$. arrosor when $P$. prideaux was absent or present in low numbers. Individuals of $L$. vulgaris reached at 30 days a survival rate of $10.1 \%$ and a mean size of $5.1 \mathrm{~mm}$ ML. When zoeal total length represents one half or less of the $L$. vulgaris $\mathrm{ML}$, it was found neccesary to offer a larger prey; thus live mysidacean shrimp (5-15 mm length) were used from day 30 (Table 2); in fact the mysidaceans were actively captured from day 35. L. vulgaris individuals of LV2 attained a survival rate at 50 days of $1.4 \%$ and a mean size of $11.7 \mathrm{~mm} \mathrm{ML}$.

Octopus vulgaris at hatching ranged in size from 1.85 to $2.12 \mathrm{~mm} \mathrm{ML} \mathrm{(mean}=1.97 \mathrm{~mm}$, s.d. $=0.06, n=30$ ). O. vulgaris was reared at a mean temperature of $21.6^{\circ} \mathrm{C}$ (OV1 experiment) using zoeae of $P$. prideaux as a main source of food, mixed with Artemia nauplii and zoeae of the portunid crab, Liocarcinus depurator (Table 2). Individuals attained a mean size of $3.14 \mathrm{~mm} \mathrm{ML}$ at 19 days. At 25 days a survival rate of $73.4 \%$ was attained, but thereafter a mass mortality of unknown origin brought the experiment to an end after 32 days. During the initial 25-day period, zoeae hatched from the spawns of 103 ovigerous females of $L$. depurator and from 115 females of $P$. prideaux were used.

Octopus vulgaris was reared at a mean temperature of $21.2^{\circ} \mathrm{C}$ (OV2 experiment) using zoeae of $L$. depurator as a main source of food for the first 10 days to stimulate first feeding. Thereafter, $P$. prideaux zoeae were used as a main food source during the planktonic stage (Table 2). Individuals attained at 30 days a survival rate of $34.6 \%$ and a mean size of 4.5 $\mathrm{mm}$ ML. First benthic individuals of $O$. vulgaris appeared at 47 days, when the diet for these individuals was changed to small portions $(5-10 \mathrm{~mm})$ of ovaries of the crab Carcinus maenas. Individuals attained mean a size of $8.6 \mathrm{~mm} \mathrm{ML}$ at the age of 60 days and a survival rate of $0.8 \%$. During the OV2 experiment, the zoeae hatched from the spawns of 152 ovigerous females of $L$. depurator and of $632 P$. prideaux were used.

\section{Discussion}

The use of decapod zoeae as food for rearing cephalopods is probably limited to cephalopod species with small to medium size at hatching. The present results show that first feeding and growth in planktonic cephalopod paralarvae can be successfully stimulated using decapod zoeae with a total length equivalent to $50-100 \%$ of the cephalopod's mantle length. In the case of Loligo vulgaris ( $3.1 \mathrm{~mm} \mathrm{ML}$ at hatching), zoeae of $P$. prideaux ( 3.1 $\mathrm{mm}$ total length) can be used as food from hatching to a size of about $7 \mathrm{~mm}$ ML. From this point onwards, larger prey is required, so mysidacean shrimp can be used during the juvenile stage. Small mysidacean shrimp (2-3 mm length) used for rearing hatchlings and then large mysis without telson were employed as food for L. vulgaris by Boletzky (1979), reaching a survival rate of $2.8 \%$ at 7 days but sizes to $7.8 \mathrm{~mm} \mathrm{ML}$ at 28 days (at temperatures between 18.5 and $22^{\circ} \mathrm{C}$ ) and $7.5 \mathrm{~mm} \mathrm{ML}$ at 75 days (at temperatures declining from 18 to $12^{\circ} \mathrm{C}$ ). Turk et al. (1986) used zooplankton collected at sea (mostly copepods $0.5-1.5 \mathrm{~mm}$ body length), Mysidopsis spp. (3.1-6.5 mm) and Palaemonetes spp. (2.2-2.8 mm) to feed L. vulgaris for the first 2 months, reaching a maximum size of $11 \mathrm{~mm}$ ML at 64 days (inean temperature $15.6^{\circ} \mathrm{C}$ ) and $9.2 \mathrm{~mm} \mathrm{ML}$ at 54 days (mean temperature $17.5^{\circ} \mathrm{C}$ ). The same authors used large prey as squid grow to a larger size, e.g. Palaemonetes spp. (10-15 mm) 
and small fishes (10-20 mm), obtaining juvenile individuals $74 \mathrm{~mm}$ ML at 140 days (mean temperature $17.5^{\circ} \mathrm{C}$ ).

The present results show that in the case of Octopus vulgaris ( $2 \mathrm{~mm} \mathrm{ML}$ at hatching), first feeding and growth can be successfully stimulated using as food zoeae of $L$. depurator ( $1.3 \mathrm{~mm}$ total length), to reach individual sizes in $O$. vulgaris around $3 \mathrm{~mm}$ ML. From this point, $P$. prideaux zoeae can be used to reach pre-benthic stages of $O$. vulgaris individuals, and then inert food (such as crah ovaries) can be used. The only previous experiment known from the literature that successfully reached the benthic stage in $O$. vulgaris was by Itami et al. (1963). Comparison of the results of these authors with the results reported here are not easy, given the systematic status of $O$. vulgaris (Hochberg et al., 1992) and different rearing temperature regimes $\left(24.7^{\circ} \mathrm{C}\right.$, against $21.2^{\circ} \mathrm{C}$ in the present results). Itami et al. (1963) reported that at 30 days, the mean size was $6 \mathrm{~mm} \mathrm{ML}$ and survival rate $18 \%$ (against $4.5 \mathrm{~mm} \mathrm{ML}$ and $34.6 \%$ survival rate in the present results); and at 60 days, the mean size was $15 \mathrm{~mm} \mathrm{ML}$ and survival rate $5 \%$ (against $8.6 \mathrm{~mm} \mathrm{ML}$ and $0.8 \%$ survival rate in the present results). Itami et al. (1963) employed different sizes of reared Palaemon serrifer zoeae as food (from 2-3 to $7 \mathrm{~mm}$ length), and, as in the present results, the use of decapod crustacean zoeae appeared to be a good method of rearing octopodid paralarval cephalopods.

In this context, the use of Pagurus prideaux to obtain a rcgular supply of zocac as food for rearing the paralarval and juvenile stages of cephalopods offers the following advantages: (a) ovigerous $P$. prideaux females occur all the year round, they have a high fertility rate, spawn several times between moults, are sexually mature from $12 \mathrm{~mm} \mathrm{SL}$ and thus offer a good daily source of food; (b) the probability of the presence of parasites or microbial infections associated with recently hatched zoeae is very low, which represents a hygienic advantage in comparison with grown prey; (c) because of their size, swimming behaviour, and distribution in the water column, these zoeae are a suitable live prey for loliginids and planktonic octopodids during the first weeks of life, and probably for other groups of cephalopods and marine zooplanktivores during the early stages of development; (d) the size and features of the zoeae at hatching vary within narrow limits, so researchers can be certain of the characteristics of the food eaten by cephalopod paralarvae or juveniles, which contributes to standardization of different experiments and feeding regimes; (e) rearing ovigerous $P$. prideaux females is simple, since this species is easily kept in aquaria without special requirements. The 3 tanks used in the present study can be placed one on top of the other, whereby the surface area occupied is $3 \mathrm{~m}^{2}$ and the total water supply required is about $9001 \cdot \mathrm{h}^{-1}$. This rearing unit may be readily expanded to meet different research needs. In addition, $P$. prideaux zoeae can themselves be reared on Artemia sp. nauplii from zoeal stage I to zoeal stage IV, i.e. to a total length of $4.2-5.8 \mathrm{~mm}$ between days 25 and 29 (Goldstein and Bookhout, 1972).

There are some 800 known species of hermit crabs (Ingle, 1993), and some of these may also be candidates for future exploitation in other regions of the world. Ameyaw-Akumfi (1975) reported that the hermit crabs, Clibanarius chapini (Schmitt) and Clibanarius senegalensis Chevreux and Bouvier, breed continuously all the year round off Ghana. These species can be collected at low tide in water no deeper than $0.25 \mathrm{~m}$. C. chapini females produce between 354 and 2215 eggs, while $C$. senegalensis females produce between 301 and 1894 eggs (Ameyaw-Akumfi, 1975). Reese (1968) reported that more than $50 \%$ of 
the females of the hermit crab Carcinus laevimanus (Randall), collected in the intertidal zone off Hawaii between April and October were uvigerous.

For future culture of paralarval and juvenile cephalopods attempted in different parts of the world, it would be worthwhile to make a preliminary study of the local crustacean fauna. Several abundant crustacean species can be selected in the area that are easy to collect and maintain in aquaria, with adequate fecundity and suitable larval characteristics. In this respect, hermit crabs are highly adaptable, and spawning activity is not dependent upon a single factor such as temperature (Reese, 1968). Furthermore, hermit crabs 'with a relatively poor supply of shells reproduce at smaller sizes, reproduce more frequently and have larger clutches' (Bertness, 1981, p. 772), thus making these crustaceans relatively easy to keep and manipulate in aquaria. They are therefore serious candidates for future use in aquaculture and experimental studies on paralarval and juvenile cephalopods.

\section{Acknowledgements}

The author wishes to thank Dr. S. von Boletzky for his helpful comments and his critical reading of the manuscript and the staff of the Laboratoire Arago for the facilities provided. Two anonymus reviewers provided helpful comments on the manuscript. The author is also grateful to Mr. Pere Pagès (Llança, Spain) and Mr. Vicenç Negre (Port Vendres, France), respective masters of the fishing vessels 'Llibertat' and 'Chevalier', for their kind cooperation in collecting part of the material employed. This study was funded by CAICYT project no. MAR91-0860 and by a postdoctoral grant from the Spanish Ministry of Science.

\section{References}

Abelló, P., 1989. Reproduction and moulting in Liocarcinus depurator (Linnaeus, 1758) (Brachyura: Portunidae) in the Northwestern Mediterranean sea. Sci. Mar., 53: 127-134.

Abelló, P., Valladares, F.J. and Castellón, A., 1988. Analysis of the structure of decapod crustacean assemblages of the Catalan coast (North-West Mediterranean). Mar. Biol., 98: 39-49.

Ameyaw-Akumfi, C., 1975. The breeding hiology of two sympatric species of tropical intertidal hermit crabs, Clibanarius chapini and C. senegalensis, Mar. Biol., 29: 15-28.

Bertness, M.D., 1981. Pattern and plasticity in tropical hermit crab growth and reproduction. Am. Nat., 117: 754773.

Boletzky, S. v., 1974. Elevage de céphalopodes en aquarium. Vie Milieu, 24: 309-340.

Boletzky, S. v., 1979. Observations on the early post-embryonic development of Loligo vulgaris (Mollusca, Cephalopoda). Rapp. Comm. Int. Mer Médit., 25/26(10): 155-158.

Boletzky, S. v., 1989. Elevage de céphalopodes en aquarium: acquis récents. Bull. Soc. Zool. Fr., 114: 57-66.

Boletzky, S. v. and Hanlon, R.T., 1983. A review of the laboratory maintenance, rearing and culture of cephalopod molluscs. Mem. Nat. Mus. Vict., 44: 147-187.

Fotheringham, N., 1980. Effects of shell utilization on reproductive patterns of tropical hermit crabs. Mar. Biol., 55: $287-293$.

Goldstein, B. and Bookhout, C.G., 1972. The larval development of Pagurus prideaux Leach, 1814, under laboratory conditions (Decapoda, Paguridea). Crustaceana, 23: 263-281.

Hamazaki, H., Fukunaga, K., Yoshida, Y. and Maruyama, K., 1991. Effects of marine microalgae Nannochloropsis sp., on survival and growth of rearing pelagic paralarvae of Octopus vulgaris, and results of mass culture in a tank of 20 metric tons. Saibai-giken, 19: 75-84 (in Japanese). 
Hanlon, R.T., 1987. Mariculture. In: P.R. Boyle (Editor), Cephalopod Life Cycles, 2. Academic Press, London, pp. 291-305.

Hanlon, R.T., Yang, W.T., Turk, P.E., Lee, P.G. and Hixon, R.F. 1989. Laboratory culture and estimated life span of the Eastern Atlantic squid, Loligo forbesi Steenstrup, 1856 (Mollusca: Cephalopoda). Aquacult. Fish. Manage., 20: 15-34.

Hazlett, B.A., 1981. Agonistic behaviour in Pagurus prideaux Leach, 1815 (Decapoda, Anomura). Crustaceana, 41: 307-310.

Hochberg, F.G., Nixon, M. and Toll, R.B. 1992. Order Octopoda Leach, 1818. In: M.J. Sweeney, C.F.E. Roper, K.M. Mangold, M.R. Clarke and S. von Boletzky (Editors), 'Larval' and Juvenile Cephalopods: A Manual for Their Identification. Smith. Cont. Zool., 513: 213-279.

Ingle, R.W., 1991. Larval Stages of Northeastern Atlantic Crabs. An Illustrated Key. Natural History Museum Publications, Chapman and Hall, London, $382 \mathrm{pp}$.

Ingle, R.W., 1993. Hermit Crabs of the Northeastern Atlantic Ocean and Mediterranean Sea. Natural History Museum Publications, Chapman and Hall, London, $495 \mathrm{pp}$.

Itami, K., Izawa, Y., Maeda. S. and Nakai, K., 1963. Notes on the laboratory culture of the octopus larvae. Bull. Jpn. Soc. Sci. Fish., 29: 514-520 (in Japanese, with English abstract).

Meadows, P.S. and Mitchell, K.A., 1973. An analysis of inter- and intraspecific aggregations in two sympatric species of hermit crab (Decapoda, Anomura, Paguridae). Mar. Behav. Physiol., 2: 187-196.

Passarella, K.P. and Hopkins, T.L., 1991. Species composition and food habits of the micronektonic cephalopod assemblage in the Eastern Gulf of Mexico. Bull. Mar. Sci., 49: 638-659.

Reese, E.S., 1968. Annual breeding seasons of three sympatric species of tropical hermit crabs, with a discussion of factors controlling breeding. J. Exp. Mar. Biol. Ecol., 2: 308-318.

Ross, D.M., 1984. The symbiosis between the 'cloak anemone' Adamsia carciniopados (Otto) (Anthozoa Actiniaria) and Pagurus prideauxi Leach (Decapoda - Anomura). Boll. Zool., 51: 413-421.

Turk, P.E., Hanlon, R.T., Bradford, L.A. and Yang, W.T., 1986. Aspects of feeding, growth and survival of the European squid Loligo vulgaris Lamarck, 1799, reared through the early growth stages. Vie Milieu, 36: 9-13.

Vecchione, M., 1987. Juvenile ecology. In: P.R. Boyle (Editor), Cephalopod Life Cycles, 2, Academic Press, London, pp. 61-84.

Vecchione, M., 1991. A method for examining the structure and contents of the digestive tract in paralarval squids. Bull. Mar. Sci., 49: 300-308.

Yang, W.T., Hixon, R.F., Turk, P.E., Krejci, M.E., Hulet, W.H. and Hanlon, R.T., 1986. Growth, behaviour, and sexual maturation of the market squid, Loligo opalescens, cultured through the life cycle. Fish. Bull., 84: 771798. 